\title{
Théophile Gautier, Euvres complètes. Critique théâtrale
}

\section{Cecilia Rizza}

\section{(2) OpenEdition \\ 1 Journals}

\section{Edizione digitale}

URL: http://journals.openedition.org/studifrancesi/9295

DOI: 10.4000/studifrancesi.9295

ISSN: 2421-5856

Editore

Rosenberg \& Sellier

\section{Edizione cartacea}

Data di pubblicazione: 1 juin 2008

Paginazione: 212

ISSN: 0039-2944

\section{Notizia bibliografica digitale}

Cecilia Rizza, «Théophile Gautier, Euvres complètes. Critique théâtrale», Studi Francesi [Online], 154 (LII I

I) | 2008, online dal 30 novembre 2015, consultato il 12 janvier 2021. URL: http://

journals.openedition.org/studifrancesi/9295 ; DOI: https://doi.org/10.4000/studifrancesi.9295

Questo documento è stato generato automaticamente il 12 janvier 2021.

\section{(c) (i) (9)}

Studi Francesi è distribuita con Licenza Creative Commons Attribuzione - Non commerciale - Non opere derivate 4.0 Internazionale. 


\title{
Théophile Gautier, Euvres complètes. Critique théâtrale
}

\author{
Cecilia Rizza
}

\section{NOTIZIA}

THÉOPHILE GAUTIER, CEuvres complètes. Critique théâtrale, t. I, 1835-1838, texte établi, présenté et annoté par Patrick BERTHIER avec la collaboration de François BRUNET, Paris, Honoré Champion, 2007 («Textes de littérature moderne et contemporaine»), pp. 921.

1 Nell'ambito di un importante progetto di edizione di tutti gli scritti di Gautier che ha già visto la pubblicazione nel 2003-2004 di tre volumi della section I contenente Romans, contes et nouvelles, di un volume della section III: Théâtre et ballets, e, nel 2007, di Voyages nella section IV, esce questo primo volume Critique théâtrale della section VI. Sono qui riuniti circa un centinaio di articoli pubblicati tra il 1835 e il 1838 sul «Monde dramatique», «La Charte de 1830», «Le Figaro», ma soprattutto, a partire dal 1837, su «La Presse» di E. de Girardin, cui Gautier dedica ormai prevalentemente la sua collaborazione. L'unica raccolta finora esistente dei feuilletons dramatiques di Gautier risale al alla metà del xIX secolo quando l'editore Hetzel pubblicò con il titolo d'Histoire de l'art dramatique depuis vingt-cinq ans gli articoli di Gautier usciti su «La Presse», un'opera per la quale Gautier non aveva mostrato alcun interesse, affidando a Noël Parfait ogni scelta e consentendo all'editore di operare tutti quei tagli che avesse ritenuto necessari. Gli attuali curatori si sono proposti, invece, di rispettare i testi di Gautier, permettendosi soltanto qualche correzione riguardante la lingua e il nome di alcuni attori o artisti (ma perchè non correggere Buonarotti in Buonarroti?) e arricchendo l'edizione con precise note e rinvii ai repertorii della fine del volume. Essi hanno tuttavia creduto opportuno «tronquer un certain nombre de feuilletons pour n'en conserver dans cette section Critique théâtrale que la partie en effet théâtrale» (p. 22); scelta discutibile poichè lontana dallo stesso modo di concepire il suo lavoro da parte di Gautier. Proprio perchè il nostro Autore considerava spesso la sua opera di «feuilletoniste» poco importante sul piano più propriamente letterario e poeticamente 
creativo, le sue divagazioni o gli inserti estranei al semplice rendiconto degli spettacoli rivestono un'importanza non trascurabile e meritano di non essere separati dal contesto in rapporto al quale sono stati pensati e scritti. Come del resto si osserva giustamente nell'introduzione al volume (p.13), questi articoli permettono di cogliere la verve di Gautier, la sua arte di scrittore anche là dove l'argomento trattato non lo consente o non lo merita. Ulteriore pregio di questa edizione che consente agli studiosi la lettura di testi talvolta difficilmente consultabili o leggibili, è di offrire un panoramo molto ampio e articolato di quanto viene rappresentato sulle scene parigine in quegli anni. Si troveranno, infatti, accanto ai rendiconti di opere più propriamente drammatiche, al riassunto e al commento dei testi messi in scena, al giudizio sugli attori, numerosi contributi su opere liriche, balletti, pantomime, spettacoli circensi ecc., sui loro interpreti e sulla più o meno favorevole ricezione del pubblico.

2 Molto utili gli «Annexes»: Répertoires des noms et des titres les plus souvent cités, Index des noms de personnes, des titres des œuvres de Gautier, des titres des œuvres scéniques, des titres de périodiques, des titres d'autres œuvres. Piuttosto limitate le indicazioni bibliografiche specificatamente riguardanti gli studi su Théophile Gautier critico. 